\title{
Examining the relationship between religious orientation and eating disturbances
}

\author{
Melissa H. Smith \\ Brigham Young University - Provo \\ P. Scott Richards \\ Brigham Young University - Provo, scott_richards@byu.edu \\ Christopher J. Maglio \\ Truman State University
}

Follow this and additional works at: https://scholarsarchive.byu.edu/facpub

Part of the Student Counseling and Personnel Services Commons

\section{Original Publication Citation}

Smith, M. H., Richards, P. S., \& Maglio, C. J. (2004). Examining the relationship between religious orientation and eating disturbances. Eating Behaviors, 5, 171-180.

\section{BYU ScholarsArchive Citation}

Smith, Melissa H.; Richards, P. Scott; and Maglio, Christopher J., "Examining the relationship between religious orientation and eating disturbances" (2004). Faculty Publications. 3856.

https://scholarsarchive.byu.edu/facpub/3856 accepted for inclusion in Faculty Publications by an authorized administrator of BYU ScholarsArchive. For more information, please contact ellen_amatangelo@byu.edu. 


\title{
Examining the relationship between religious orientation and eating disturbances
}

\author{
Melissa H. Smith ${ }^{\mathrm{a}, \mathrm{b}, *}$, P. Scott Richards ${ }^{\mathrm{a}, \mathrm{b}}$, Christopher J. Maglio ${ }^{\mathrm{c}}$ \\ ${ }^{a}$ Brigham Young University, Provo, UT, USA \\ ${ }^{\mathrm{b}}$ Center for Change, Orem, UT, USA \\ ${ }^{\mathrm{c}}$ Truman State University, Kirksville, MO, USA
}

Accepted 22 July 2003

\begin{abstract}
The relationship between religion and eating concerns is receiving increasing empirical attention. The current investigation sought to examine the relationship between eating attitudes and religious orientation, utilizing the fourfold typology of religious orientation. A curvilinear relationship was found between religious orientation and eating attitudes among a subclinical college population and a clinical population of individuals receiving inpatient treatment for eating disorders, particularly among extrinsically orientated individuals with diagnosis of bulimia nervosa.
\end{abstract}

(C) 2003 Elsevier Ltd. All rights reserved.

Keywords: Eating disorders; Religious orientation; Eating attitudes; Bulimia nervosa; Anorexia nervosa; Religion

\section{Introduction}

Anorexia nervosa and bulimia nervosa have received a great deal of media attention and have been the focus of much research. The debilitating effects of these disorders continue to plague individuals, especially young women, as research estimates that $95 \%$ of individuals with anorexia and $90 \%$ of individuals with bulimia are women (Killian, 1994). Consequently, most research and treatment interventions focus on women.

* Corresponding author. Center for Change, 1790 North State Street, Orem, UT 84057, USA. Tel.: +1-801-224-8255; fax: $+1-801-224-8301$.

E-mail address: mhs@email.byu.edu (M.H. Smith). 
Eating disorders are particularly common among female college students. Several researchers have documented the high incidence of eating disorders and eating disordered behavior on college campuses (Schwitzer, Bergholz, Dore, \& Salimi, 1998). In one study approximately 25\% of female undergraduate college students reported that their eating was out of control (Koszewski, Newell, \& Higgins, 1990). In another study, 30\% of female college students reported extreme worries about body image, while $25 \%$ had extreme worries about weight control (Delene \& Bragowicz, 1990).

Sociocultural influences, including religion, have been purported to play a significant role in the etiology, treatment, and prevention of eating disorders. While there has been little research focused specifically on religion and eating disorders, Richards et al. (1997) noted that the small body of research that does exist in this field supports religiosity and spirituality as important aspects of eating disorders.

Historically, religion and eating disorders have been connected, most notably through descriptions of fasting saints (Joughin, Crisp, Halek, \& Humphrey, 1992; Vandereycken \& Van Deth, 1990). Romney and Goli (1992) point out that fasting saints expressed their spirituality through control of their bodies, including abstinence from food, and that today individuals with eating disorders attain "personal salvation" as they attempt physical perfection. Other relationships between religion and eating disorders have been proposed, some of which contradict one another (Joughin et al., 1992). Some claim that a distinct religious culture may shield women with eating concerns from seeking treatment early, thus prolonging pathology (Joughin et al., 1992). Another explanation relates to asceticism, the practice of strict self-denial as a measure of personal and especially spiritual discipline (Merriam-Webster's Collegiate Dictionary, 1995). Some claim that asceticism may be used as a justification for continuing an eating disorder (Joughin et al., 1992).

Sykes, Gross, and Subishin (1986) found a significant relationship between eating disorders and religion, with eating disorders being most prevalent among Catholics and Jews. These researchers also noted that a higher number of Catholics and Jews had eating disorders than would be expected for the given populations (Sykes et al., 1986; Sykes, Leuser, Melia, \& Gross, 1988).

One aspect of religion that has provoked anxiety for individuals with eating concerns is religious activities involving food. Graham, Spencer, and Andersen (1991) found that individuals with eating disorders had altered religious practices, including avoidance of Holy Communion and other religious activities in which food is a part, resulting in many women feeling extreme guilt.

In a study investigating the connection between religion and eating disorders, Joughin et al. (1992) found that women claiming to be religious had the lowest body mass index (BMI) when compared to their counterparts, and that the perceived conflict between religious guidelines and eating disturbances decreased as BMI decreased. Results showed that the degree of weight loss in anorexia nervosa was associated with the relative importance of religion (Joughin et al., 1992). Notably, Joughin et al. (1992) point out that asceticism may be used as justification, supplementation, and replacement for anorexic weight loss. This finding supports the position that asceticism may serve as a defense in the perpetuation of anorexia. Further, Joughin et al. (1992) (p. 404) point out that counseling is a "major challenge" when eating disorders seem to be confused with, or justified by, religious beliefs.

In contrast to the findings on anorexia, results of individuals with bulimia show that as pathology increases, importance of religion decreases, indicating that as bulimics "give in" to the binge-purge cycle, there is a decrease in religious belief (Joughin et al., 1992). The individual may believe that she 
has sinned by binging and purging and, therefore, may discard religion and the guilt associated with it. Conversely, the individual with anorexia may increase in spirituality as she continually denies herself, possibly using asceticism as a defense (Joughin et al., 1992).

Because religion seems to be important to many women with eating concerns, it may be beneficial to investigate the role religion plays and ways that religion might be employed therapeutically. Important to understanding eating disturbances is examining whether there is a relationship between eating disorders and religious orientation, and whether individuals of certain religious orientations have a greater prevalence of eating disorders than do others.

The purpose of the present study was to examine the relation between religious orientation and eating attitudes among clinical and nonclinical samples. Two questions were asked in this investigation. First, does a relationship exist between religious orientation and eating disorder symptoms among a nonclinical sample of female college students and/or among women beginning inpatient treatment for eating disorders? Next, does a relationship exist between religious orientation and eating disorder symptoms according to eating disorder diagnosis (anorexia nervosa, bulimia nervosa, and eating disorder not otherwise specified). These questions were examined utilizing Pearson correlations, as well as the fourfold typology of religious orientation (Donahue, 1985; Richards, 1991).

\section{Method}

\subsection{Subjects}

The present study included two sample groups. The first sample consisted of 129 female undergraduate students enrolled in general psychology courses at Truman State University (TSU sample), a small Midwestern university, during the Fall Semester of 2000. Mean age of students was 19, with ages ranging between 18 and 22. Of the students, 17 were seniors, 29 were juniors, 77 were sophomore, and 6 were freshman. The majority of TSU sample participants were Caucasian $(n=124)$, with 2 African American participants, 1 Hispanic participant, and 2 participants categorized as "Other." Regarding religious affiliation, 50 participants identified themselves as Catholic, 35 participants said they were Protestant, 34 categorized themselves as "Other," 9 classified themselves as "None" (i.e., having no religious affiliation), and 1 participant said she was Jewish.

The second sample included 316 females beginning inpatient treatment of eating disorders at a private treatment facility specializing in the treatment of eating disorders (CFC sample). These participants ranged in age from 12 to 56, with a mean age of 21. Of the subjects, 185 were LDS, 15 were Protestant, 12 were Catholic, 3 were Jewish, 15 categorized themselves as "None," and 21 categorized themselves as "Other"; religious affiliation information was missing on 65 participants.

Regarding ethnicity of the second sample, 257 participants were Caucasian, 2 participants were Black, 1 participant was Asian, 1 participant was Hispanic, and 4 participants identified themselves as "Other"; data were missing on 51 participants. Educational level of the second sample included 8 participants at junior high level, 59 participants at high school level, 45 high school graduates, 114 participants at college level, 26 college graduates, 3 participants at graduate level, and 2 participants with graduate degrees; educational information was missing for 35 participants. 
Of 278 participants in the second sample for whom diagnostic information was available, 108 participants had been given a diagnosis of anorexia nervosa, 93 participants had received a diagnosis of Eating Disorder NOS, and 77 participants had been given a diagnosis of bulimia nervosa.

\subsection{Procedure}

Participants at TSU were recruited through general psychology courses with the permission of professors, and the research was conducted during the first 10-15 min of regularly scheduled classes. Subjects were informed of the purpose of the current study, apprised of the issues regarding informed consent, and given an informed consent statement. Return of the survey was proof of consent for the TSU sample. While the TSU sample was largely nonclinical, a subsample of TSU participants scoring 14 or above on the 26-item Eating Attitudes Test (EAT) was obtained $(n=25)$, indicating more disturbances in eating attitudes among this subsample. We believe that the TSU subsample is most likely comprised of women with bulimic symptoms, given the higher prevalence of bulimic symptoms, as opposed to anorexic symptoms, on college campuses (Hesse-Biber \& Marino, 1991; Klemchuk, Hutchinson, \& Frank, 1990; Mintz \& Betz, 1988; Schwitzer et al., 1998; Sykes et al., 1986).

Participants at CFC completed the measures as part of their initial battery of assessment measures, which were administered within the first week of being admitted to the inpatient unit. Prior to completion of the measures, participants were informed that the data would be used for research and evaluation purposes, were informed of their rights as research participants, and signed an informed consent form. Participants completed the measures under the supervision of either a unit nurse or one of two psychology technicians.

\subsection{Measures}

\subsubsection{Eating Attitudes Test (EAT)}

The EAT is a 26-item test designed to assess attitudes and behaviors similar to those in clinically diagnosed eating disorders. Participants rate the frequency with which they experience 26 statements, using a six-point scale; subscales include dieting, bulimic behaviors, and self-control of eating behavior (Hewit, Flett, \& Ediger, 1995). Garner and Garfinkel (1980) report that the EAT is effective for assessing a wide range of attitudes and behaviors characteristic of eating disorders and is capable of identifying individuals with eating disturbances. While high scores on the EAT do not necessarily equate with clinical eating disorders, many of the characteristics represented are the same as those found in anorexia, and the EAT is considered to be an appropriate screening device for eating disorders. Cronbach's alpha is .85 , and a cutoff of 20 is believed to reliably identify disturbed eating.

The EAT has been widely tested for reliability and validity and has been found to be a reliable and valid measure of eating problems (Fisher, Pastore, Schneider, Pegler, \& Napolitano, 1994; Hesse-Biber \& Marino, 1991). For instance, reports indicate an alpha reliability coefficient of .79 for anorexia and .94 for pooled anorexic and normal controls, along with a test-retest reliability coefficient of .84 (HesseBiber \& Marino, 1991). Further, Garner, Olmsted, Bohr, and Garfinkel (1984) found that 83.6\% of cases based on the EAT were correctly classified.

An extension of the EAT 26, the EAT 40 includes additional questions pertaining to eating attitudes and behaviors. While the EAT 26 was utilized for the first sample of TSU students, inpatient participants completed the EAT 40. 


\subsubsection{Religious orientation scale (ROS)}

The ROS is one of the most widely used scales for assessing religious orientation (Donahue, 1985; Trimble, 1997). Developed by Allport and Ross (1967), it consists of 20 items, with 11 items measuring extrinsic religiosity (E) and 9 items measuring intrinsic religiosity (I). Extrinsic individuals view their religion as a way of achieving status or acceptance, while intrinsic individuals internalize their beliefs and "live their religion." Since its development, the ROS, specifically the intrinsic-extrinsic frame of reference, has received support as an effective way to assess religiosity (Bergin, Masters, \& Richards, 1987). Reliabilities of the ROS range from .69 to .93 (Donahue, 1985). Trimble (1997, p. 983) reports that while the intrinsic scale has respectable internal consistency reliability, the extrinsic scale "lacks precision" with regard to internal consistency. In Allport and Ross' conceptualization of religious orientation, they proposed the possibility of two additional orientations, which were further clarified by Richards (1991) as a proreligious group and a nontraditionally religious group.

As individuals in the proreligious group adhere to both intrinsic and extrinsic items on the ROS, they can be considered orthodox and dogmatically devout (Richards, 1991). Intrinsic individuals adhere strongly to intrinsic items on the ROS, and can be described as orthodox, devout, and motivated towards religion because of personal beliefs. In contrast, extrinsic individuals reject intrinsic items and strongly adhere to extrinsic items on the ROS. These individuals pursue religion for social reasons and are not considered orthodox. Finally, the nontraditionally religious group, sometimes referred to as nonreligious, are those individuals who adhere to neither intrinsic or extrinsic items on the ROS; they reject the dictates of traditional religion. Some have suggested that using the fourfold typology in assessing religious orientation can be more illuminating than simply investigating intrinsic and extrinsic orientations (Donahue, 1985; Richards, 1991).

The Body Shape Questionnaire (BSQ) (Cooper, Taylor, Cooper, \& Fairburn, 1987) is a 34-item selfreport measure, which assesses concerns about body shape in individuals with eating disorders. Higher scores indicate more distress surrounding issues related to an individual's body shape, such as feeling too fat, wanting to be thinner, or feeling ashamed and self-conscious about one's body. The BSQ demonstrated good internal consistency, with item correlation at .60 or above in a sample of patients and nonpatients (Cooper et al., 1987). Validity studies on the BSQ have been associated with higher scores on several other measures of eating disorders. Further, individuals with bulimia scored higher on the questionnaire than those who did not have bulimia (Cooper et al., 1987), and higher scores were also related to certain psychopathologies including depression and low self-esteem (Cooper \& Fairburn, 1993).

\subsection{Data analysis and design}

The current research data were evaluated using correlation analysis, analysis of variance (ANOVA), and multivariate analysis of variance (MANOVA). The present study included examination of six data sets: TSU sample, TSU subsample, CFC sample, CFC-anorexia nervosa, CFC-bulimia nervosa, and CFC-eating disorder NOS. Specifically, the TSU sample, consisting of 129 female undergraduate students, was largely nonclinical. TSU participants scoring 14 or above on the 26-item EAT, indicative of some degree of eating disturbances, comprised the TSU subsample. The CFC sample was composed of 315 females beginning inpatient treatment for eating disorders, and this sample was further delineated according to diagnosis, resulting in three CFC subsamples: CFC-anorexia nervosa, CFC-bulimia nervosa, and CFC-eating disorder NOS. 
Pearson correlations were conducted between the I and E subscales of the ROS and the EAT and BSQ for each subsample. To better understand the relationship, if any, between religious orientation and eating attitudes, the fourfold typology of religious orientation was employed, with midpoints on the I and E scales of the ROS (27 and 33) being used as cutoffs for the four types. Participants in the four categories were then compared according to EAT and BSQ scores. Further, differences among inpatient participants were investigated according to diagnosis (anorexia nervosa, bulimia nervosa, eating disorder NOS).

\section{Results}

A Pearson correlation of EAT scores and intrinsic and extrinsic orientations, as presented in Table 1, revealed a significant relationship between EAT scores and an extrinsic orientation among the TSU subsample $(.402, P<.05)$ and the CFC-bulimia nervosa sample $(.315, P<.01)$. Further, examination of BSQ scores and religious orientation revealed a significant relationship between BSQ scores and an extrinsic orientation among the CFC participants with a diagnosis of bulimia nervosa $(.270$, $P<.05)$.

Employing the fourfold typology of religious orientation, the investigators sought to better understand the relationship, if any, between specific religious orientations and eating disorder symptoms. Multivariate analysis of variance (MANOVA) and the associated means and standard deviations presented in Table 2 revealed that when TSU sample participants $(n=129)$ in the four religious orientation groups were compared according to EAT scores, although there was no significant main effect for either intrinsicness or extrinsicness, there was a significant Intrinsicness $\times$ Extrinsicness interaction effect $(F=7.963, P<.01)$. Similarly, a significant interaction effect $(F=5.399, P<.01)$ was

Table 1

Pearson correlations of ROS with EAT and BSQ according to data set

\begin{tabular}{|c|c|c|}
\hline \multirow[t]{2}{*}{ Scale and data set } & \multicolumn{2}{|l|}{ ROS subscale } \\
\hline & Intrinsic orientation & Extrinsic orientation \\
\hline \multicolumn{3}{|l|}{ EAT } \\
\hline TSU sample $(n=129)$ & -0.01 & -0.14 \\
\hline TSU Subsample $(n=25)$ & 0.14 & $0.40^{*}$ \\
\hline CFC sample & -0.02 & 0.05 \\
\hline CFC-anorexia nervosa & -0.10 & 0.15 \\
\hline CFC-bulimia nervosa & $0.26^{*}$ & $0.32 * *$ \\
\hline CFC-NOS & -0.10 & -0.16 \\
\hline \multicolumn{3}{|l|}{$B S Q$} \\
\hline CFC sample & -0.04 & 0.09 \\
\hline CFC-anorexia nervosa & -0.08 & 0.13 \\
\hline CFC-bulimia nervosa & 0.10 & $0.27 *$ \\
\hline CFC-NOS & -0.13 & -0.12 \\
\hline
\end{tabular}

$* P<.05$.

$* * P<.01$. 
Table 2

Means, standard deviations, and $F$ tests for the religious typology groups on dependent measures according to data set

\begin{tabular}{|c|c|c|c|c|c|c|c|}
\hline \multirow[t]{2}{*}{ Scale and data set } & \multicolumn{4}{|c|}{ Religious orientation $^{\mathrm{a}}$} & \multicolumn{3}{|c|}{$F$ test $^{\mathrm{b}}$} \\
\hline & I, M (S.D.) & P, M (S.D.) & NT, M (S.D.) & E, M (S.D.) & I & $\mathrm{E}$ & $\mathrm{IE}$ \\
\hline \multicolumn{8}{|l|}{$E A T$} \\
\hline TSU sample $(n=129)$ & $7.35(6.19)$ & $11.13(13.59)$ & $9.73(9.47)$ & $4.14(6.30)$ & 1.92 & 0.29 & $7.96^{* *}$ \\
\hline TSU Subsample $(n=25)$ & $18.75(4.20)$ & $32.75(15.28)$ & $24.80(6.14)$ & $22.67(6.66)$ & 0.34 & 2.92 & $5.40 * *$ \\
\hline CFC sample (Total) & $60.01(21.27)$ & $62.50(23.68)$ & $63.04(23.86)$ & $62.71(23.81)$ & 0.29 & 0.13 & 0.23 \\
\hline CFC-anorexia nervosa & $62.72(22.48)$ & $69.47(22.60)$ & $65.83(22.26)$ & $71.64(28.21)$ & 0.25 & 1.39 & 0.01 \\
\hline CFC-bulimia nervosa & $55.74(18.42)$ & $68.06(19.43)$ & $51.19(24.45)$ & $66.67(18.00)$ & 0.28 & $6.10 *$ & 0.08 \\
\hline CFC-NOS & $61.82(22.51)$ & $59.68(25.89)$ & $72.56(18.72)$ & $54.10(19.34)$ & 0.23 & 3.67 & 2.30 \\
\hline \multicolumn{8}{|l|}{$B S Q$} \\
\hline CFC sample & $146.80(38.16)$ & $153.77(36.38)$ & $153.09(35.73)$ & $154.88(35.23)$ & 0.41 & 1.11 & 0.24 \\
\hline CFC-anorexia nervosa & $134.90(41.90)$ & $151.93(33.87)$ & $133.44(41.58)$ & $142.50(38.06)$ & 0.01 & 1.35 & 0.04 \\
\hline CFC-bulimia nervosa & $149.00(36.76)$ & $162.59(23.44)$ & $152.50(33.54)$ & $177.00(19.92)$ & $4.75^{*}$ & 0.41 & 0.25 \\
\hline CFC-NOS & $160.51(29.04)$ & $153.74(37.17)$ & $169.94(23.23)$ & $168.20(23.20)$ & 0.16 & 0.30 & 0.05 \\
\hline
\end{tabular}

TSU sub=Truman State University Subsample; CFC-BN1 = Center for Change Bulimia Nervosa Diagnosis-Body Shape Questionnaire (BSQ); CFC-BN2 = Center for Change Bulimia Nervosa Diagnosis-Eating Attitudes Test (EAT); Eating Disorder Symptoms $=\mathrm{EAT} \& \mathrm{BSQ}$ scores as $z$ scores; $\mathrm{P}=$ proreligious group; $\mathrm{NT}=$ nontraditionally religious group; $\mathrm{I}=\mathrm{intrinsically}$ religious group; $\mathrm{E}=$ extrinsically religious group.

${ }^{\mathrm{a}} \mathrm{I}=$ intrinsically religious group; $\mathrm{P}=$ proreligious group; $\mathrm{NT}=$ nontraditionally religious group; $\mathrm{E}=$ extrinsically religious group.

${ }^{\mathrm{b}} \mathrm{I}=$ intrinsic main effect; $\mathrm{E}=$ extrinisic main effect; $\mathrm{IE}=$ Intrinsic $\times$ Extrinsic interaction effect.

$* P<.05$.

$* * P<.01$.

\section{Curvilinear Relationship of Eating Disorder Symptoms According to Religious Typology Groups}

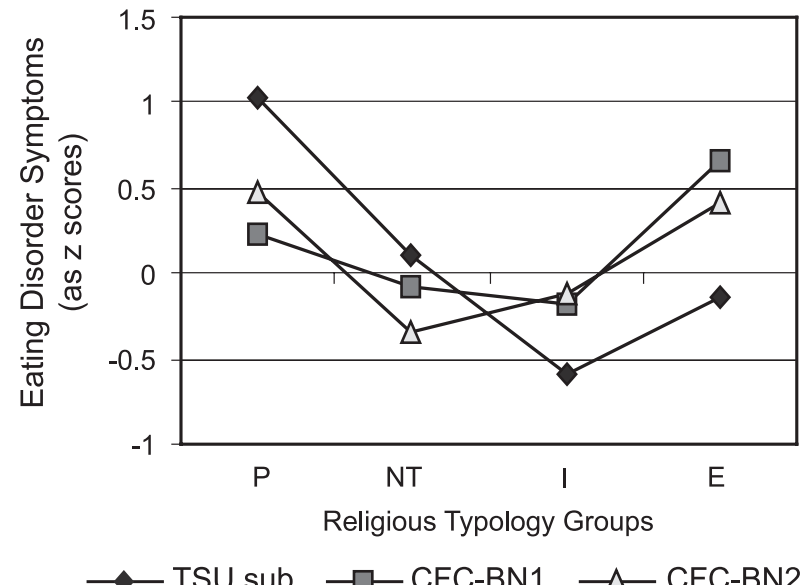

Fig. 1. Curvilinear relationship of eating disorder symptoms according to religious typology groups. 
found among TSU subsample participants $(n=25)$. Finally, a significant main effect for extrinsicness $(F=6.099, P<.05)$ was found among CFC participants with a diagnosis of bulimia nervosa. The relationship between EAT and BSQ scores and the fourfold religious typology is shown visually in Fig. 1 , where it can be seen that a curvilinear relationship exists.

\section{Discussion}

There were several noteworthy findings in this study. First, Pearson correlation analyses revealed positive relationships between eating disorder symptoms (EAT and BSQ) and extrinsic religiousness among women with bulimia nervosa or subclinical bulimic symptoms (TSU subsample). Second, the fourfold typology revealed a curvilinear relationship among religious orientation and eating disorder symptoms among women with bulimia or subclinical bulimic symptoms. Indiscriminately proreligious and extrinsic people (those scoring high on extrinsicness) tended to have more eating disorder symptoms, whereas intrinsic and nontraditionally religious women (those scoring low on extrinsicness) tended to have fewer symptoms.

These findings seem to point to one conclusion: that is, women who are involved in religion for extrinsic reasons (for personal and social gains and acceptance) tend to have more eating disorder symptoms. Women with more concern about the external, social aspects of religious involvement tend to be more susceptible to bulimia.

This finding is consistent with the clinical observation that while individuals with anorexia may find religious justification for their extreme behaviors (Joughin et al., 1992), individuals with bulimia often disconnect spiritually as they engage in binge-purge behaviors (Joughin et al., 1992). So while individuals with bulimia may engage in religious activities for social reasons, they may experience an internal spiritual disconnection (Hardman, Berrett, \& Richards, submitted for publication), a process lending to a more extrinsic religious orientation.

As the bulimia pathology increases, a bulimic "gives in" to the binge-purge cycle, and she may believe that she has sinned by binging and purging; she therefore discards religion and the guilt associated with it. Conversely, the individual with anorexia may not feel this guilt as she continually denies herself, if she is religious and can use asceticism as a defense (Joughin et al., 1992).

Third, intrinsic religiousness was not consistently associated with eating disorder symptoms, among women with either bulimia or anorexia. Thus, this suggests that devout, mature religious involvement does not necessarily contribute to eating disorder symptoms.

\subsection{Limitations}

Given that the majority of the TSU sample did not fit clinical parameters of eating disorders, a correlation between eating disturbances and religious orientation would not be expected. However, of those in the TSU sample who did display some significant eating disturbances (TSU subsample), a significant correlation was found. Yet, the TSU subsample was small, and implications are necessarily limited. Certainly, no causal relations can be made from the present study, and it must be noted that the significant correlation found among the TSU subsample consisted of a small sample of women. Finally, before we can be confident about our findings that bulimia is related to an extrinsic religious orientation, the present study needs to be replicated. 


\section{Conclusions}

Future research would do well to examine in depth the relationship between religious orientation and eating disorders. For instance, is there a causal relationship between specific religious orientations and tendencies to be prone to eating disturbances? Further, what processes occur for the individual with a spiritual orientation over the course of an eating disorder? Is there, as has been proposed (Hardman et al., submitted for publication), a spiritual disconnection for the individual suffering with an eating disorder? And if so, how does this spiritual disconnection impact treatment? The present study is an initial investigation of religious orientation and eating disturbances; it represents a call for more research of eating disorders and spirituality.

\section{References}

Allport, G. W., \& Ross, J. M. (1967). Personal religious orientation and prejudice. Journal of Personality and Social Psychology, 5, 432-443.

Bergin, A. E., Masters, K. S., \& Richards, P. S. (1987). Religiousness and mental health reconsidered: A study of an intrinsically religious sample. Journal of Counseling Psychology, 34(2), 197-204.

Cooper, P. J., \& Fairburn, C. G. (1993). Confusion over the core psychopathology of bulimia nervosa. International Journal of Eating Disorders, 13(4), 385-390.

Cooper, P., Taylor, M., Cooper, Z., \& Fairburn, C. (1987). The development and validation of the Body Shape Questionnaire. International Journal of Eating Disorders, 6(4), 485-494.

Delene, L. M., \& Bragowicz, A. A. (1990). Student healthcare needs, attitudes, and behavior: Marketing implications for college health centers. Journal of American College Health, 38, 157-164.

Donahue, M. J. (1985). Intrinsic and extrinsic religiousness: Review and meta-analysis. Journal of Personality and Social Psychology, 48, 400-419.

Fisher, M., Pastore, D., Schneider, M., Pegler, C., \& Napolitano, B. (1994). Eating attitudes in urban and suburban adolescents. International Journal of Eating Disorders, 16(1), 67-74.

Garner, D. M., \& Garfinkel, P. E. (1980). Socio-cultural factors in the development of anorexia nervosa. Psychological Medicine, 10, 647-656.

Garner, D. M., Olmsted, M. P., Polivy, J., \& Garfinkel, P. E. (1984). Comparison between weight-preoccupied women and anorexia nervosa. Psychosomatic Medicine, 46(3), 255-266.

Graham, M. A., Spencer, W., \& Andersen, A. E. (1991). Altered religious practices in patients with eating disorders. International Journal of Eating Disorders, 10(2), 239-243.

Hardman, R. K., Berrett, M. E., \& Richards, P. S. (2002). Spirituality and ten false pursuits of eating disorders. (submitted for publication).

Hesse-Biber, S., \& Marino, M. (1991). From high school to college: Changes in women's self-concept and its relationship to eating problems. Journal of Psychology, 125(2), 199-216.

Hewit, P. L., Flett, G. L., \& Ediger, E. (1995). Perfectionism traits and perfectionistic self-presentation in eating disorder attitudes, characteristics, and symptoms. International Journal of Eating Disorders, 18(4), 317-326.

Joughin, N., Crisp, A. H., Halek, C., \& Humphrey, H. (1992). Religious belief and anorexia nervosa. International Journal of Eating Disorders, 12(4), 397-406.

Killian, K. D. (1994). Fearing fat: A literature review of family systems understandings and treatments of anorexia and bulimia. Family Relations, 43, 311-318.

Klemchuk, H. P., Hutchinson, C. B., \& Frank, R. I. (1990). Body dissatisfaction and eating-related problems on the college campus: Usefulness of the eating disorder inventory with a nonclinical population. Journal of Counseling Psychology, 37(3), 297-305.

Koszewski, W. M., Newell, G. K., \& Higgins, J. J. (1990). Effect of a nutrition education program on the eating attitudes and behaviors of college women. Journal of College Student Development, 31, 203-210. 
Merriam-Webster's Collegiate Dictionary. (10th ed.) (1995). Springfield, MA: Merriam-Webster.

Mintz, L. B., \& Betz, N. E. (1988). Prevalence and correlates of eating disordered behaviors among undergraduate women. Journal of Counseling Psychology, 35(4), 463-471.

Richards, P. S. (1991). Religious devoutness in college students: Relations with emotional adjustment and psychological separation from parents. Journal of Counseling Psychology, 38(2), 189-196.

Richards, P. S., Hardman, R. K., Frost, H. A., Berrett, M. E., Clark-Sly, J. B., \& Anderson, D. K. (1997). Spiritual issues and interventions in the treatment of patients with eating disorders. Eating Disorders, 5(4), 261-279.

Romney, P., \& Goli, M. (1991). Projective identification and eating disorders on a college campus. Journal of College Student Psychotherapy, 6(1), 53-74.

Schwitzer, A. M., Bergholz, K., Dore, T., \& Salimi, L. (1998). Eating disorders among college women: Prevention, education, and treatment responses. Journal of American College Health, 46, 199-206.

Sykes Jr., D. K., Gross, M., \& Subishin, S. (1986). Preliminary findings of demographic variables in patients suffering from anorexia nervosa and bulimia. International Journal of Psychosomatics, 33(4), 27-30.

Sykes Jr., D. K., Leuser, B., Melia, M., \& Gross, M. (1988). A demographic analysis of 252 patients with anorexia nervosa and bulimia. International Journal of Psychosomatics, 35(1-4), 5-9.

Trimble, D. E. (1997). The religious orientation scale: Review and meta-analysis of social desirability effects. Educational and Psychological Measurement, 57(6), 970-86.

Vandereycken, W., \& Van Deth, R. (1990). From fasting saints to anorexic girls: The history of self-starvation. New York: New York University Press. 